\title{
Global Market Dynamics of Korean Cosmetics: Network Analysis of International Trade
}

\author{
Song-yi Youn, University of Missouri \\ Kyu-Hye Lee, Hanyang University
}

Keywords: Korean cosmetic products, international trade, network analysis

\section{Introduction}

As the global market for cosmetic products continues to expand, South Korea serves as a leader among countries in the cosmetics industry. The volume of international trade increased. Exports of cosmetic products reached \$1.24 billion in 2013 and $\$ 4.96$ billion in 2017. This figure is about a four-time increase within 4 years (Shin, 2018). It presents an average annual growth rate of 41.3\%. Considerably, the import of cosmetic products reached $\$ 1.55$ billion in 2017, accounting for $\$ 3.41$ billion of trade surplus. As a result of the increased exportation of media contents, specifically Korean dramas and movies (e.g., K-drama, K-pop), experts of cosmetic products surged. The reason is based on the government policy that support exports of small and medium-sized enterprises (SMEs) in South Korea (Squier, 2016). According to the report from the Korea International Trade Association (http://www.kita.org/), cosmetic products exported in South Korea shared $22.1 \%$ of the beauty market in China in 2015. Significantly, the share increased to $32.1 \%$ in 2017. Reports and research (e.g., Yang \& Kim, 2019) indicated that the success of Korean cosmetic brands in China is due to a "Korean wave" in China. In addition, the volume of exports in cosmetic products to the United States from South Korea increased by $45.66 \%$, compared to the previous year. However, network changes, within global network connections in the world's cosmetic industries amid South Korea remain unclear. Therefore, the purpose of this study is to define the global patterns of the international trade of cosmetic products from the perspective of network analysis. Its design examines South Korea's centralities within the international network of cosmetic products trade.

\section{Literature Review}

Social network analysis is regarded as a useful tool for analyzing real world phenomena as it is composed of complex networks (Mercer, 2015). Researchers in the field of world trade mentioned that network analysis is a practical method to complement traditional trade research and to analyze the individual characteristics of export countries and network influence (Anderson $\&$ Van Wincoop, 2003). The focus of network analysis is based on relationships within a network. These relationships present implications for exploring patterns among social entities, according to relational changes (Anderson \& Van Wincoop, 2003). In particular, indicators of centrality identify the most influential nodes (i.e., countries) within the network (Freeman, Roeder \& Mulholland, 1979). Therefore, this study examined centrality indicators (i.e., eigenvector, betweenness) that quantitatively represent the structural importance within the international trade network. According to Serrano and Boguñá (2003), structural importance is

Page 1 of 3

Published under a Creative Commons Attribution License (https://creativecommons.org/licenses/by/4.0/), which permits unrestricted use, distribution, and reproduction in any medium, provided the original work is properly cited.

ITAA Proceedings, \#76 - https: //itaaonline.org 
increasing in order to understand the world trade network. Therefore, this study used SNA to visualize the international trade network of cosmetic products and analyze network structure of each country within the world network.

\section{Methods}

This study analyzed the international trade of cosmetic products using network analysis. Countries are nodes and trade flows are network links. For comparison, data in 2006 and 2016 were collected and used for analysis. The world trade value was used in Uncomtrade (https://comtrade.un.org). Selected top 16 export countries, based on the global trade values of these countries, were over $85 \%$ of the world export value in both 2006 and 2016 . The commodity code used was HS Code 3304. It includes beauty, make-up, skin care, and manicure (or pedicure) products. Researchers coded each connection among selected countries and export values. Data were used for final analysis. UCINET and NetDraw software were used for analyzing networks. According to countries in the network, in/out degree, eigenvector centrality and betweenness centrality were calculated. Figure 1 and Figure 2 displays visualized trade networks in 2006 and 2016.

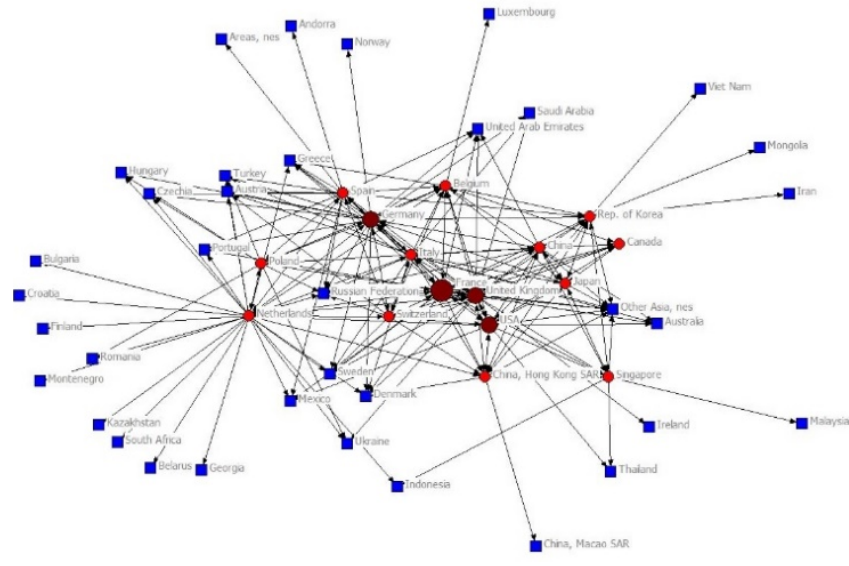

Figure 1. International trade network in 2006

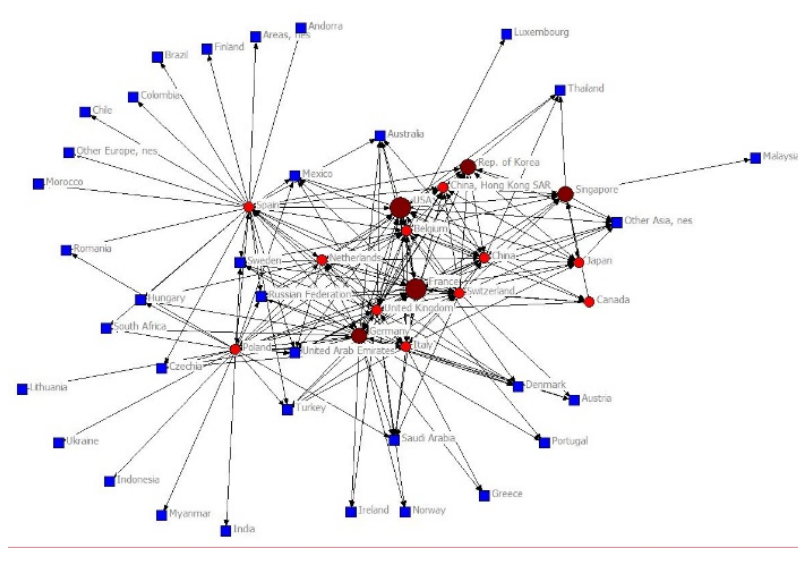

Figure 2. International trade network in 2016

\section{Results}

Regarding world export ranks by country, France, United States, and Germany were linked within the top five countries in both 2006 and 2016. This report indicates that these countries consistently lead the world cosmetic industry. The United States represents the second largest exporter; values remained similar (11.86\% in 2006 and $11.18 \%$ in 2016). By comparison, South Korea's world export value accounted for 16th place in $2006(1.21 \%)$, and it rose to third place in 2016 (8.14\%). This result reinforces the notion that Korea's cosmetic product industry made remarkable growth over the past decade.

Published under a Creative Commons Attribution License (https://creativecommons.org/licenses/by/4.0/), which permits unrestricted use, distribution, and reproduction in any medium, provided the original work is properly cited.

ITAA Proceedings, \#76 - https://itaaonline.org 
Although Korea's world ranking increased dramatically, its influence on the network overall remained about the same (eigenvector centrality, .180 in 2006) (.187 in 2016). These figures indicate that the quantity of trade increased; however, quality remained consistent. Moreover, eigenvector centrality registered similar figures (.251 in 2006) (.264 in 2016). Betweenness centrality decreased (54.243 in 2016) (4.497 in 2016). This figure indicates that Korea's influence decreased as it relates to connecting other influential countries within the world network. Also, this result revealed that Korea's export value depended mostly on countries identified as peripheral actors in the world trade network. The reason may be due to the fact that the country exported only to countries mostly located in Asia (i.e., China, Hong Kong, Japan, Thailand, other ASEAN countries).

\section{Conclusions}

Results imply that while other leading countries, France and the United States, wielded similarly influential power over time, Korea is a major player in the world's cosmetic trade but holds less controlling power over international trade networks. From the perspective of Korean cosmetic products, this study offered dynamic perspectives for analyzing international trade using network analysis.

\section{References}

Anderson, J. E., \& Van Wincoop, E. (2003). Gravity with gravitas: A solution to the border puzzle. American Economic Review, 93(1), 170-192.

Freeman, L. C., Roeder, D., \& Mulholland, R. R. (1979). Centrality in social networks:

Experimental results. Social Networks, 2(2), 119-141.

Mercer, S. (2015). Social network analysis and complex dynamic systems. In Zoltán Dörnyei, Peter D. MacIntyre, \& Alastair Henry (Eds.), Motivational dynamics in language learning (pp. 73-82). Tonawanda, NY: Multilingual Matters.

Serrano, M. A., \& Boguñá, M. (2003). Topology of the world trade web. Physical Review E, $68(1), 015101$.

Shin, M. S. (2018). Analysis of cosmetic product exports. Korea Health Industry Development Institute Brief, 262, 1-8.

Squier. C. (2016, April 6). How South Korea became the beauty capital of the world. Retrieved from https://graziadaily.co.uk/beauty-hair/hair/korean-beauty-products-good/

Yang, H-Y, \& Kim, S-C. (2019). The purpose of this paper is to study the influence of Chinese women's purchasing behavior on Korean cosmetics. Korea Trade Review, 44(1), 101-113.

Page 3 of 3

(c) 2019 The author(s). Published under a Creative Commons Attribution License (https://creativecommons.org/licenses/by/4.0/), which permits unrestricted use, distribution, and reproduction in any medium, provided the original work is properly cited.

ITAA Proceedings, \#76 - https: //itaaonline.org 